ORIGINAL ARTICLE

\title{
Long term cognitive development in children with prolonged crying
}

\author{
M R Rao, R A Brenner, E F Schisterman, T Vik, J L Mills
}

Arch Dis Child 2004;89:989-992. doi: 10.1136/adc.2003.039198

See end of article for authors' affiliations .....................

Correspondence to: Dr M R Rao, National Institute of Allergy and Infectious Diseases, 6610 Rockledge Drive-Room 5095, Bethesda, MD 20892-6603, USA; mr8u@nih.gov

Accepted 28 February 2004 Background: Long term studies of cognitive development and colic have not differentiated between typical
colic and prolonged crying. Objective: To evaluate whether colic and excessive crying that persists beyond 3 months is associated with adverse cognitive development.

Design: Prospective cohort study. A sample of 561 women was enrolled in the second trimester of pregnancy. Colic and prolonged crying were based on crying behaviour assessed at 6 and 13 weeks. Children's intelligence, motor abilities, and behaviour were measured at 5 years $(n=327)$. Known risk factors for cognitive impairment were ascertained prenatally, after birth, at 6 and 13 weeks, at 6, 9, and 13 months, and at 5 years of age.

Results: Children with prolonged crying (but not those with colic only) had an adjusted mean IQ that was 9 points lower than the control group. Their performance and verbal $I Q$ scores were 9.2 and 6.7 points lower than the control group, respectively. The prolonged crying group also had significantly poorer fine motor abilities compared with the control group. Colic had no effect on cognitive development.

Conclusions: Excessive, uncontrolled crying that persists beyond 3 months of age in infants without other signs of neurological damage may be a marker for cognitive deficits during childhood. Such infants need to be examined and followed up more intensively.
U ncontrolled and unexplained excessive crying that begins in the first few weeks of life in otherwise healthy babies is usually referred to as infantile colic. ${ }^{1} \mathrm{~A}$ systematic review of published reports suggests that infantile colic is a relatively common condition with rates between $5 \%$ and $40 \%$, depending on the methods used to identify and classify it. ${ }^{2}$ While factors that have been associated with colic include maternal smoking during pregnancy, socioeconomic status, maternal diet, infant diet, and low birth weight, the aetiology is largely unknown..$^{3-14}$ Colic can be extremely stressful for families. Fortunately, there appears to be no impact of colic on long term cognitive development, although there are suggestions of early transient developmental delays. ${ }^{15}$ As colic resolves spontaneously and rarely persists beyond 3 months of age, most prospective studies of this condition have only monitored crying during the first 3 months. ${ }^{2}$ However, a recent study that followed children with unexplained crying until 6 months identified an association between persistent crying during infancy and hyperactivity when the children were between 8 and 10 years old. ${ }^{16}$

Our aim in this study was to determine whether prolonged excessive crying that lasts beyond 3 months of age is associated with abnormal cognitive development.

\section{METHODS}

\section{Assembly of study subjects}

The current study is an analysis of data from the control arm of a study designed to identify risk factors for, and outcomes of, children born small for gestational age (SGA). Details of the larger study are described elsewhere. ${ }^{17}$ Briefly, the study was conducted at the university hospitals of Trondheim and Bergen in Norway and Uppsala in Sweden. Between January 1986 and March 1988, a 10\% random sample of women with one or two previous singleton births presenting for prenatal care before 20 weeks of gestation were approached for enrolment into the control group of the SGA study. This control group was used for the current analysis. The study was approved by ethics committees at each site.

\section{Maternal factors}

After written informed consent, data were obtained on maternal characteristics, smoking behaviour at the time of conception, and socioeconomic status. When the children were 5 years old, Raven's progressive matrices were used to evaluate the mother's non-verbal problem solving abilities as a measure of maternal intelligence quotient (IQ). ${ }^{18}$ After delivery, information was obtained from medical records on events relating to obstetric history and the newborn infant. Infants with major congenital anomalies or with gestational age less than 37 weeks were excluded from this analysis. Information on maternal smoking was obtained at enrolment and during pregnancy. As the smoking status during pregnancy was missing for some mothers during follow up visits, maternal smoking was defined as smoking at the time conception occurred.

\section{Infant measurements}

Infants were evaluated by public health nurses during routine preventive care visits at 6 and 13 weeks and at 6, 9, and 13 months of age, and mothers were questioned about their infant's diet and behaviour. Mothers were queried about "symptoms of colic" at the sixth and 13th week, and at the 6 and 9 month visits, qualified with an explanation of "daily uncontrolled crying without any obvious cause, persisting for at least two weeks". Colic was defined as unexplained infant crying reported within the first 12 weeks of life but not beyond. "Prolonged crying" was defined as "daily uncontrolled crying without any obvious cause, persisting for at least 2 weeks" but in contrast to colic, was

Abbreviations: PDMS, Peabody developmental motor scales; PIC, personality inventory for children; $P \mathrm{IQ}$, performance intelligence quotient; SGA, small for gestational age; VIQ, verbal intelligence quotient 
reported both at 6 weeks of age and at the 13 week visit. Durations of exclusive and complementary breast feeding were based on the detailed history of the infant's diet. ${ }^{19}$ When the children were 13 months old, a home screening questionnaire was completed at the Norwegian sites to assess the quality of the home environment in which the child was being raised.$^{20}$ When the children were 5 years of age, all mothers provided a detailed history of the child's major health problems.

\section{Outcomes}

At the two study sites in Norway, psychometrists administered the Fagan test of infant intelligence at 6 months of age. ${ }^{21}$ At 5 years, all sites used the WPPSI-R (Wechsler preschool and primary scales of intelligence-revised) to assess intelligence. ${ }^{22}$ This test assesses the total IQ using standardised verbal IQ (VIQ) and performance IQ (PIQ) measures. Gross and fine motor abilities were measured using the Peabody developmental motor scales (PDMS). ${ }^{23}$ To identify behavioural problems, a battery of tests based on the personality inventory for children (PIC) was administered when the child was 5 years old.$^{24}$ Like the Fagan test, the PIC was done only at the two Norwegian sites. Individuals administering all the above tests were blinded to the history of colic and prolonged crying reported by the mother during follow up.

\section{Statistical methods}

Infants whose mothers reported no crying related problems were considered to be the reference group and were compared with those with prolonged crying and colic. Twogroup comparisons were carried out using the non-parametric Mann-Whitney U test and Fisher's exact test. Logistic regression was used to identify factors associated with colic or with prolonged crying, after adjusting for confounding factors. For associations with cognitive outcomes, multiple linear regression models were used to adjust for the confounding effects of maternal education, age, smoking, and infant sex. Choice of confounders was based on prior scientific knowledge of factors associated with colic and cognitive development.

\section{RESULTS}

\section{Study population}

Of 521 eligible deliveries, 407 (78\%) had follow up information for the sixth week and the 13th week preventive care visits. Five year follow up IQ was obtained on 327 (80\%) of these children. The sociodemographic characteristics and anthropometric measurements at birth for the 114 infants and their mothers who did not have follow up information did not differ from those who returned for follow up at the 6 week and 13 week visits. Similarly, as described elsewhere,

\begin{tabular}{|c|c|c|c|}
\hline & Normal $(n=264)$ & Colic $(n=48)$ & $P C(n=15)$ \\
\hline \multicolumn{4}{|l|}{ Site of enrolment } \\
\hline Uppsala & $96(36 \%)$ & $16(33 \%)$ & $5(33 \%)$ \\
\hline Bergen & $90(34 \%)$ & $13(27 \%)$ & $6(40 \%)$ \\
\hline Trondheim & $78(30 \%)$ & $19(40 \%)$ & $4(27 \%)$ \\
\hline Family income (US\$)* & $3745(1521)$ & $3844(1177)$ & $4008(1308)$ \\
\hline \multicolumn{4}{|l|}{ Maternal characteristics } \\
\hline Maternal age (years) & $29.6(3.9)$ & $29.9(4.0)$ & $32.0(5.2) \dagger$ \\
\hline Maternity leave $\ddagger$ & $8.7(3.6)$ & $9.6(3.5)$ & $10.6(4.0)$ \\
\hline Parity 1 & $181(69 \%)$ & $34(71 \%)$ & $10(67 \%)$ \\
\hline \multirow{2}{*}{\multicolumn{4}{|c|}{ Education }} \\
\hline & & & \\
\hline$<10$ years & $42(16 \%)$ & $4(9 \%)$ & $1(7 \%)$ \\
\hline $10-11$ years & $72(27 \%)$ & $13(28 \%)$ & $4(27 \%)$ \\
\hline High school & $62(24 \%)$ & $11(23 \%)$ & $2(13 \%)$ \\
\hline Trade school & $67(25 \%)$ & 16 (34\%) & $5(33 \%)$ \\
\hline University & $20(8 \%)$ & $3(6 \%)$ & $3(20 \%)$ \\
\hline Maternal IQ§ & $48.9(6.3)$ & $48.2(7.1)$ & $48.5(10.1)$ \\
\hline Smoker (conception) & $90(34 \%)$ & $22(46 \%)$ & $3(20 \%)$ \\
\hline Body mass index $\left(\mathrm{kg} / \mathrm{m}^{2}\right)$ & $21.9(2.8)$ & $22.2(2.9)$ & $21.9(2.3)$ \\
\hline Home screening score & $35.4(2.9)$ & $35.2(2.9)$ & $36.0(2.9)$ \\
\hline \multicolumn{4}{|l|}{ Infant characteristics } \\
\hline Male & $127(48 \%)$ & $24(50 \%)$ & $5(33 \%)$ \\
\hline Admitted to $\mathrm{NICU}^{* *}$ & $14(5 \%)$ & $1(2 \%)$ & $0(0 \%)$ \\
\hline Serum ferritin $(\mu \mathrm{g} / \mathrm{l})+\dagger$ & $156(97)$ & $152(85)$ & 164 (112) \\
\hline Birth weight (g) & $3705(512)$ & $3617(594)$ & $3597(468)$ \\
\hline Head circumference $(\mathrm{cm})$ & $35.4(1.2)$ & $35.2(1.3)$ & $34.9(1.2)$ \\
\hline Ponderal index $\left(\mathrm{g} / \mathrm{cm}^{3}\right)$ & $2.77(0.25)$ & $2.79(0.21)$ & $2.70(0.21)$ \\
\hline 5 min Apgar score $\geqslant 8$ & $254(97 \%)$ & $47(100 \%)$ & $15(100 \%)$ \\
\hline Attended kindergarten & $197(77 \%)$ & $39(85 \%)$ & $12(86 \%)$ \\
\hline Exclusively breast fed (weeks) & $13.9(7.5)$ & $12.2(7.7)$ & $12.8(7.3)$ \\
\hline Any breast feeding (weeks) & $28.2(14.8)$ & $28.1(16.2)$ & $29.7(14.6)$ \\
\hline \multicolumn{4}{|c|}{ 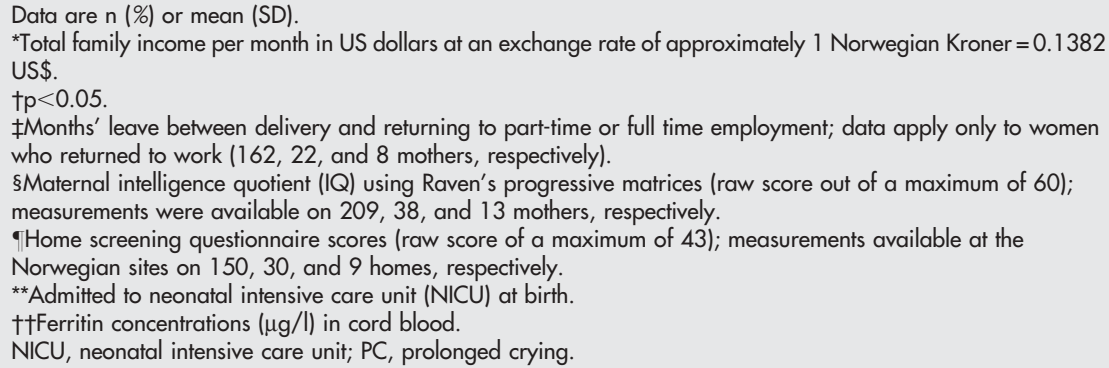 } \\
\hline
\end{tabular}


children with no IQ measurements at 5 years did not differ from those with measurements, as they had comparable durations of breast feeding, sociodemographic factors, and growth. ${ }^{19} 25-27$

\section{Factors associated with colic and prolonged crying}

Of 63 mothers reporting colic at the 6 week visit, 15 were classified as having prolonged crying because the behaviour persisted at the 13th week. Maternal and infant characteristics of normal infants, infants with colic, and prolonged crying were comparable (table 1). The three groups did not differ in obstetric complications such as gestational diabetes, hypertension, emergency caesarean sections, premature rupture of membranes, placenta praevia, or obstructed labour; neither did they differ in neonatal factors including birth trauma, resuscitation in the delivery room, admission to the neonatal intensive care units, presence of metabolic disturbances, and treatments for neurological or pulmonary disorders. After adjusting for maternal education and age, mothers who were smokers at the time of conception were twice as likely to report infants with colic than those who did not smoke (odds ratio $=2.1$ (95\% confidence interval $(\mathrm{CI})$, 1.1 to 4.0$) ; \mathrm{p}<0.05)$. However, smoking was not associated with prolonged crying ( $\mathrm{OR}=0.7$ (95\% CI, 0.2 to 2.1$)$ ).

\section{Cognitive development}

Children who had prolonged crying, but not those who had colic, had poorer outcomes on many of the tests of cognitive development. For infants with Fagan's test measurements, the adjusted mean novelty score for the prolonged crying group was 4.8 points lower than for the comparison group ( $95 \%$ CI, 0.6 to $9.0 ; \mathrm{p}<0.05$ ), while there was no significant difference between the colic group and the comparison group.

At 5 years of age, using the distribution of the total IQ scores of the children with no colic as the reference, $47 \%$ (seven of 15) of the prolonged crying children had total IQ scores below the 25 th centile. Of these, $20 \%$ (three of 15) had total IQ scores below the 5th centile. The adjusted mean difference in total IQ for the prolonged crying group was 9.0 points lower (95\% CI, 1.9 to $16.2 ; \mathrm{p}<0.05$ ) than in children who had no problems associated with crying (table 2). Subscales indicated a 9.2 point deficit (95\% CI, 2.0 to 16.5; $\mathrm{p}<0.05$ ) in performance IQ and a 6.7 point deficit $(95 \%$ CI, -0.3 to $13.8 ; p=0.06$ ) in verbal IQ for these children. Although there were no significant differences in the PDMS scores for gross motor abilities such as balance and locomotion, the prolonged crying group had significantly poorer fine motor skills measured by PDMS eye-hand coordination scores $(\mathrm{p}<0.05)$. The PIC scores at 5 years of age in a subset of nine children in the prolonged crying group and 165 in the comparison group suggested that children in the prolonged crying group were more likely to have problems associated with discipline $(\mathrm{p}<0.05)$ and with hyperactivity $(\mathrm{p}<0.05)$; no such differences were apparent for the colic group (data not shown).

\section{DISCUSSION}

Our data corroborate most previous findings that transient colic does not affect cognitive development. On the other hand, prolonged crying (crying that continues beyond 3 months) was associated with a significantly increased risk of cognitive problems at 5 years of age. In this study population, prolonged crying was associated with lower IQ scores, poorer fine motor abilities, hyperactivity, and discipline problems during childhood. There were no apparent neurological or clinical signs in the prolonged crying group that would have identified these infants as being at high risk for poor cognitive development. Thus these findings indicate that prolonged crying itself may be a marker of subsequent impaired cognitive development.

Our conclusions are based on only 15 children classified as prolonged criers. Hence larger and more definitive studies need to be conducted to corroborate the findings. However, despite the small number of children in the prolonged crying group, statistically significant differences were detected for many of the outcomes because there were large intergroup differences. To explore the possibility that other factors might have caused an association between prolonged crying and cognitive development, we compared the home environments in which the children were reared and found no differences across the groups. We also examined iron status and found that ferritin levels in cord blood were similar (table 1). Children with prolonged crying had no major health problems such as heart disease, seizures, problems with hearing and sight, recurrent otitis media or diarrhoea, cerebral palsy, asthma, or speech problems that could account for the lower IQs observed. Iron deficiency or lead poisoning can impair cognitive development, but high serum lead concentrations and severe anaemia are rare in this population..$^{29}$ Iron levels were not low in the prolonged crying group.

Many definitions have been used to define colic, ${ }^{2}$ the most common being Wessel's criteria. ${ }^{28}$ We used a pragmatic definition described by Schmitt which is based on parental perception of what may be abnormal and uncontrolled crying. ${ }^{1}$ In this study, colic and prolonged crying were determined prospectively but relied purely on maternal

Table 2 Intelligence quotient (IQ) scores of children who were normal, had colic, and had prolonged crying

\begin{tabular}{|c|c|c|c|c|c|}
\hline & Normal $(n=264)$ & Colic $(n=48)$ & PC $(n=15)$ & $\begin{array}{l}\text { Adjusted difference } \dagger \\
\text { (colic } v \text { normal) }\end{array}$ & $\begin{array}{l}\text { Adjusted difference } \dagger \\
\text { (PC v normal) }\end{array}$ \\
\hline $\begin{array}{l}\text { Fagan } \neq \\
\text { WPPSI-R§ }\end{array}$ & $59.3(6.2)$ & $59.2(7.2)$ & $55.5(5.6)$ & -0.3 (-2.9 to 2.2$)$ & $-4.8(-9.0 \text { to }-0.6)^{*}$ \\
\hline Total IQ & $108.7(14.7)$ & $112.8(17.0)$ & $103.5(17.6)$ & $3.9(-0.4$ to 8.2$)$ & $-9.0(-16.2$ to -1.9$)$ \\
\hline Verbal IQ & $104.0(14.2)$ & $108.5(16.8)$ & $100.5(16.6)$ & $4.3(-0.1$ to 8.5$)$ & $-6.7(-13.8$ to 0.3$)$ \\
\hline Performance IQ & 111.6 (14.7) & $113.4(14.7)$ & $105.9(16.8)$ & $1.6(-2.6$ to 5.9$)$ & $-9.2(-16.5$ to -2.0$)$ \\
\hline \multicolumn{6}{|l|}{ PDMS } \\
\hline Eye-hand & $84.9(4.7)$ & $85.0(4.3)$ & $82.7(4.8)$ & $0.0(-1.4$ to 1.3$)$ & $-3.4(-5.7 \text { to }-1.1)^{*}$ \\
\hline Locomotion & $107.1(5.7)$ & $107.0(5.8)$ & $106.2(9.0)$ & $-0.2(-1.9$ to 1.6$)$ & $-1.6(-4.6$ to 1.5$)$ \\
\hline Balance & $59.8(5.3)$ & $59.3(4.4)$ & $59.3(4.5)$ & $-0.3(-1.9$ to 1.2$)$ & $-1.2(-3.8$ to 1.5$)$ \\
\hline
\end{tabular}

Values are mean (SD) or difference in score (95\% confidence interval).

* $\mathrm{p}<0.05$.

†Difference in scores, adjusted for sex, maternal smoking, maternal age, and maternal education.

\#Fagan's test of infant intelligence measured at six months of age

\$Measured at 5 years of age.

TMeasured at 5 years of age.

PC, prolonged crying; PDMS, Peabody development motor scale; WPPSI-R, Wechsler preschool and primary scales of intelligence-revised. 
assessments without detailed recording of total duration of crying and total number of times that the child cried. Despite the lack of this level of detail, the prevalence of colic was comparable to that reported in most other studies. Furthermore, only mothers with one or more previous births were enrolled in the study. As all the mothers in this study had previous experience with one or more infants, it is less likely that reports of unusual crying would solely reflect anxiety or inappropriate perceptions of what constitutes abnormal behaviour of the infants. The finding that mothers who were smokers were twice as likely to have children with colic is consistent with the findings of most other studies, which have reported odds ratios of between 1.5 and 2.8 for the association between smoking and colic, suggesting that there was no biased assessment of colic. ${ }^{4-6}{ }^{13}$ Additionally, our ability to show that infants with prolonged crying had hyperactivity problems during childhood was consistent with other similar findings. ${ }^{16}$

Several strengths of our study need to be mentioned. Studies of cognitive outcomes require measurement of clinical, environmental, social, and behavioural variables because IQ is influenced by all these factors. As our study data were obtained prospectively during pregnancy, the intrapartum period, the neonatal period, and throughout early childhood, it was possible to assess a large number of potential causal as well as confounding factors that could provide an explanation for the poorer cognitive outcomes. In this study, the confounding effects of race and socioeconomic status are minimised because the population in this region is relatively homogeneous and health care access is universal. Reporting of events during infancy by the mothers is likely to be of high quality because most mothers are educated and are allowed 9 to 12 months of leave after delivery (almost fully paid) to care for their infants ${ }^{31}$; hence they are in a position to provide comprehensive and accurate information.

To our knowledge, none of the previously reported studies has assessed the important independent confounding effects of genetic factors such as maternal IQ and factors like the duration of exclusive breast feeding while studying the association between colic and cognitive outcomes. Our study showed an association between prolonged crying and cognitive development after controlling for these factors.

Finally, despite the small numbers in the prolonged crying group, we were able to show that many cognitive outcomes such as early infant IQ, IQ during childhood (both performance and verbal), fine motor abilities, and behavioural measures such as discipline and hyperactivity were significantly worse in this group.

It is unclear why prolonged crying is a risk factor for long term cognitive problems, and the mechanisms need to be explored. We speculate that irritability caused by subtle underlying neurological problems may be the cause of prolonged crying, despite the fact that most common neurological problems were ruled out in our population. Alternatively, children normally cry less as they mature developmentally; thus prolonged crying may be a sign of delayed maturation.

\section{Conclusions}

These data suggest that regardless of the cause, prolonged crying may provide the paediatrician with important early indications that a child is at risk of impaired cognitive development. In this population, approximately $5 \%$ of the children experienced prolonged crying, suggesting that this behaviour is not rare. Hence infants who have prolonged crying beyond 3 months of age need to be examined and followed up more intensively.

\section{Authors' affiliations}

M R Rao*, R A Brenner, E F Schisterman, J L Mills, Epidemiology Branch, Division of Epidemiology, Statistics and Prevention Research, National Institute of Child Health and Human Development, National Institutes of Health, Bethesda, Maryland, USA

T Vik, Department of Community Medicine and General Practice, Norwegian University of Science and Technology, Trondheim, Norway

*Dr Rao's current affiliation: Parasitology and International Programs Branch, National Institute of Allergy and Infectious Diseases, National Institutes of Health, Bethesda, Maryland

\section{REFERENCES}

1 Schmitt BD. Colic: excessive crying in newborns. Clin Perinatol 1985; 12:441-51.

2 Lucassen PL, Assendelff WJ, van Eijk JT, et al. Systematic review of the occurrence of infantile colic in the community. Arch Dis Child 2001;84:398-403.

3 Duro D, Rising R, Cedillo M, et al. Association between infantile colic and carbohydrate malabsorption from fruit juices in infancy. Pediatrics 2002; 109:797-805.

4 Sondergaard C, Henriksen TB, Obel C, et al. Smoking during pregnancy and infantile colic. Pediatrics 2001;108:342-6.

5 Matheson I, Rivrud GN. The effect of smoking on lactation and infantile colic. JAMA 1989;261:42-3.

6 Said G, Patois E, Lellouch J. Infantile colic and parental smoking. BMJ 1984;289:660.

7 Jakobsson I, Lindberg T. Cow's milk proteins cause infantile colic in breast-fed infants: a double-blind crossover study. Pediatrics 1983;71:268-71.

8 Lust KD, Brown JE, Thomas W. Maternal intake of cruciferous vegetables and other foods and colic symptoms in exclusively breast-fed infants. J Am Diet Assoc 1996;96:46-8.

9 Hide DW, Guyer BM. Prevalence of infant colic. Arch Dis Child 1982:57:559-60.

10 Thomas DW, McGilligan K, Eisenberg LD, et al. Infantile colic and type of milk feeding. Am J Dis Child 1987;141:451-3.

11 Nylander G, Matheson I. Breast feeding. Effects of smoking and education. Tidsskr Nor Laegeforen 1989;109:970-3.

12 van der Wal MF, van den Boom DC, Pauw-Plomp H, et al. Mothers' reports of infant crying and soothing in a multicultural population. Arch Dis Child 1998;79:312-17

13 Reijneveld SA, Brugman E, Hirasing RA. Infantile colic: maternal smoking as potential risk factor. Arch Dis Child 2000;83:302-3.

14 Sondergaard C, Skajaa E, Henriksen TB. Fetal growth and infantile colic. Arch Dis Child Fetal Neonatal Ed 2000;83:F44-7.

15 Sloman J, Bellinger DC, Krentzel CP. Infantile colic and transient developmental lag in the first year of life. Child Psychiatry Hum Dev 1990;21:25-36.

16 Wolke D, Rizzo $P$, Woods S. Persistent infant crying and hyperactivity problems in middle childhood. Pediatrics 2002;109:1054-60.

17 Bakketeig LS, Jacobsen G, Hoffman HJ, et al. Pre-pregnancy risk factors of small-for-gestational age births among parous women in Scandinavia. Acta Obstet Gynecol Scand 1993;72:273-9.

18 Raven JC. Progressive matrices. London: HK Lewis, 1965.

19 Rao MR, Hediger M, Levine R, et al. Effect of breast feeding on cognitive development of small for gestational age infants. Acta Pediatr 2002;91:267-74.

20 Andersson HW, Gotlieb SJ, Nelson KG. Home environment and cognitive abilities in infants born small-for-gestational-age. Acta Obstet Gynecol Scand Suppl 1997; 165:82-6.

21 Fagan JF. Infants' recognition memory for faces. J Exp Child Psychol 1972; 14:453-76.

22 Wechsler D. WPPSI-R manual. San Antonio: The Psychological Corporation, 1989.

23 Folio MR, Fewell RR. Peabody developmental motor scales and activity cards, Manual. Allen: DLM Teaching Resources, 1983.

24 Lachar D, Gdowski CL, Snyder DK. Broad-band dimensions of psychopathology: factor scales for the Personality Inventory for Children. $J$ Consult Clin Psychol 1982;50:634-42

25 Angelsen NK, Vik T, Jacobsen G, et al. Breast feeding and cognitive development at age 1 and 5 years. Arch Dis Child 2001;85:183-8.

26 Trasti N, Vik T, Jacobsen G, et al. Smoking in pregnancy and children's mental and motor development at age 1 and 5 years. Early Hum Dev 1999;55:137-47.

27 Sommerfelt K, Andersson HW, Sonnander K, et al. Cognitive development of term small for gestational age children at five years of age. Arch Dis Child 2000;83:25-30.

28 Wessel MA, Cobb JC, Jackson EB, et al. Paroxysmal fussing in infancy, sometimes called "colic". Pediatrics 1954;14:421-34.

29 Odland JO, Nieboer E, Romanova N, et al. Self-reported ethnic status of delivering women, newborn body mass index, blood or urine concentrations of toxic metals, and essential elements in sera of Norwegian and Russian Arctic populations. Int J Circumpolar Health 1999;58:4-13.

30 Olsen PT, Vikan H, Dramdal M, et al. Iron status and weaning practices among healthy 1-year old infants. Tidsskr Nor Laegeforen 1995; 1 15:612-14.

31 Zetterstrom R. Breastfeeding and infant-mother interaction. Acta Paediatr Suppl 1999;88:1-6. 